\title{
ESTAMPA CHITA: CESURA E MEMÓRIA NO DESCONTÍNUO DA HISTÓRIA DOS VENCEDORES
}

\author{
Chintz stamping: Cesure and memory in the discontinuous history of the winners
}

Emanuela Francisca Ferreira Silva ${ }^{1}$

\begin{abstract}
Resumo
Começo este trabalho conceituando história dos vencedores e história dos vencidos através das reflexões de Hobsbawm e Walter Benjamim. Após essa introdução, cito dois acontecimentos registrados na história tradicional: a inferioridade dos tecelões no século XVI e a tentativa de colocar os escravos brasileiros, século XIX, como desleixados e dedicados exclusivamente a trabalhos rudes e pesados. Analisando esses dois fatos, tento encontrar outro passado, tendo a memória da estampa chita como cesura, capaz de encontrar nos espaçamentos da história aquilo que lhe escapa.
\end{abstract}

Palavras-chave: Estampa chita, Cesura, História dos vencidos e dos vencedores.

\begin{abstract}
I start this work conceptualizing history of winners and losers of history through the reflections of Hobsbawm and Walter Benjamin. After this introduction, I quote two events recorded in the traditional story: the inferiority of the weavers in the sixteenth century and the attempt to bring brazilian slaves in the nineteenth century, as careless and dedicated exclusively to work rough and heavy. Analyzing these two facts I try to find another past, where the memory of the chintz as the cesura, able to find the spacing of the story what it escapes.
\end{abstract}

Key-words: Chintz, Cesura, History of the won and of the winners.

\section{Resumen}

Inicio este trabajo conceptualizando historia de los victoriosos y de los vencidos a través de las reflexiones de Hobsbawm y Walter Benjamin. Después de esta introducción, cito dos eventos registrados en la historia tradicional: la inferioridad de los tejedores en el siglo XVI y la tentativa de poner los esclavos brasilenos, en el siglo XIX, como desleyjados y dedicados exclusivamente a

\footnotetext{
${ }^{1}$ Especialista em Linguística Aplicada às Línguas e Dicente do Programa de Pós-graduação Letras, em nível de Mestrado, da Universidade Vale do Rio Verde, Unincor, campus Três Corações, sob orientação da Prof ${ }^{a}$ Dr $^{a}$ Aparecida Maria Nunes. Contato: assismusic@bol.com.br
} 
Estampa chita: cesura e memória no descontínuo da história dos vencedores

de Emanuela Francisca Ferreira Silva

trabajos rudos y pesados. Yo analiso estos dos hechos, para tentar encontrar otro pasado, em que la memoria del pintado es cesura, capaz de encontrar el espacio de la historia qué le escapa .

Palabras-clave: Pintado, Cesura, Historia de los vencidos y de los victoriosos.

\section{INTRODUÇÃO}

Preservar os grandes feitos, as tradições e os acontecimentos que marcaram as diversas civilizações, que surgiram e desapareceram ao longo do tempo, é preocupação constante de povos e governantes. A História Tradicional, que é regida por aqueles que detêm o poder econômico e escolástico, faz uso dessa necessidade humana de arquivamento para contar à sua maneira o passado transcorrido.

Segundo Hobsbawm² (1998, pp. 13-21) “[...] história é a matéria-prima para as ideologias nacionalistas ou étnicas ou fundamentalistas". Ele afirma que a profissão de historiador pode ocasionar tantos danos como a do físico nuclear, visto que, como a história é a matéria-prima para as ideologias nacionalistas ou étnicas fundamentalistas, ela pode inventar o passado se ele não for satisfatório para aqueles que detêm o poder político. Hobsbawm sugere vários exemplos para confirmar esses questionamentos, como o surgimento do Paquistão, que todos afirmam ser nação de Cinco Mil Anos, mas que como estado apenas surgiu a partir de 1947.

Assim, é preciso repensar o passado sob outra óptica. A Nova História ${ }^{3}$ começou a re-olhar o passado a partir da tradição de povos e nações que não estavam no contínuo da história de longa duração. Os defensores desse movimento instauraram a valorização do cotidiano, com temas voltados para a sexualidade, o amor, o corpo, a mulher, a família. Eles procuravam dentro da história dos vencedores, que é a história tradicional, outra história - a dos vencidos, ou seja, de fatos e pessoas, que até então, não eram requisitados ou percebidos pelas instituições de poder.

Walter Benjamim (1987) se preocupou intensamente com essas questões referentes à narração clássica, a perda da tradição do contar histórias, enfim, ele via nova teoria da historiografia revolucionária que era a rememoração salvadora do passado esquecido. Por isso a narração é fundamental para a constituição do sujeito.

\footnotetext{
${ }^{2}$ Hosbawm questionou acerca da veracidade dos fatos e acontecimentos afirmados pela história tradicional, em seu ensaio Dentro e Fora da história - que foi apresentado como conferência inaugural do ano acadêmico de 1993-4 na Universidade da Europa Central em Budapeste.Esse ensaio foi publicado posteriormente na New York Rewiw of Books (16 de dezembro de 1994, pp.62-5) com o título A nova ameaça para a história.

${ }^{3}$ Esse movimento surgiu na França, nos anos de 1960 e foi difundido pelos herdeiros da Escola dos Annales, iniciada nos anos de 1930, por Marc Bloch e Lucien Febvre.
} 
Benjamim tenta pensar a tradição dos vencidos, que não está ao nível da continuidade, mas, sobre os saltos, na interrupção e no descontínuo. "O continuum da história é o dos opressores. Enquanto a representação do continuum iguala tudo ao nível do chão, a representação do descontínuo é o fundamento da autêntica tradição" (GAGNEBIN, 2004, p.99).

É nova maneira de olhar a memória coletiva, só que aqui ele a procura nos espaços da história tradicional, nas suas margens. Enquanto ela é história dos vencedores, há outra história, a dos vencidos, que continua com a missão de resguardar a memória de povos, de tempos e de espaços. A verdade do discurso não se esgota nele, mas no que se deixou escapar do mesmo.

Esse gesto de ruptura na linha cronológica do tempo e do espaço é chamado de cesura, isto é, a paragem e o sopro marcado que escandem o uso da mesma, ao interrompê-lo. É sabido que o termo cesura vem da literatura e significa corte, a pausa na sexta sílaba do verso alexandrino. Para Benjamim a cesura tem dupla função. Primeiro, é essa crítica à história tradicional que se diz detentora da verdade absoluta no contínuo. Segundo, a cesura é a ruptura no desenvolvimento da narrativa. A cesura em nossa linguagem é o eco privilegiado da interrupção (messiânica) que destrói a continuidade, que se erige em totalidade histórica universal e salva o surgimento do sentido na intensidade do presente.

A estampa chita possui memória que ocasiona essa cesura no contínuo da história de longa duração. Ela, a chita, se encontra no descontínuo, ou seja, na história dos vencidos, em que é possível encontrar outro passado que não se encontra nos livros tradicionais, mas nas margens, naquilo que quebra a continuidade, salvando o surgimento do sentido na intensidade do presente.

Este artigo é, pois, tentativa de investigação de novo passado que se encontra no descontínuo da história tradicional, através da memória da estampa chita. Utilizo dois acontecimentos que são dicotômicos, posto que contam passado novo, quando re-olhados em suas margens. O primeiro é a suposta inferioridade dos tecelões no século XVI e o segundo, a tentativa de colocar os escravos brasileiros como desleixados e dedicados exclusivamente a trabalhos rudes e pesados.

Nesses dois exemplos, vou tentar, através de argumentos pautados na memória da chita, encontrar afirmações que tragam para o presente, novo passado que se difira daquele imposto pela história tradicional. Feita esta análise, tecerei algumas considerações finais que coloquem a memória da estampa como cesura, paragem, ou seja, o re-olhar do passado naquilo que escapa do contínuo da história tradicional. 


\section{BRASILEIROS QUE FORAM ESCRAVOS}

A palavra chita deriva de chint, em híndi, língua falada da Índia, derivada do sânscrito. Chint significa pinta ou mancha ${ }^{4}$. E caracteriza, pois, a estampa predominantemente floral, tendo em vista que o hinduísmo e o islamismo, as duas religiões principais do oriente, proibiam as representações figurativas. Então, entre 3 mil e 5 mil a.C., já podem ser encontrados flores, galhos, folhagens, arabescos e desenhos geométricos, como o madra (listras cruzadas formando xadrez, típico da região de Madras), nos tecidos que os indianos estampavam com seus cunhos, espécie de carimbo de madeira entalhada ou de metal, antecessor dos clichês de impressão.

Segundo a história tradicional, houve grande desenvolvimento da produção de tecidos estampados na Índia, do século XI ao XV. As cores vinham de pigmentos naturais, como o índigo (planta da família das leguminosas, que produz o azul) e o dióxido de ferro (ferrugem), preparados em fervura e infusões. Para fixar a cor ao tecido era utilizado o mordente, substância essa que agregada ao tingimento garantia a durabilidade da cor. Por isso, os tecidos indianos resistiam melhor que os europeus a lavagens e exposições ao sol.

Os anais históricos revelam ainda que os indianos chegavam a acrescentar urina a determinadas plantas tintórias para acelerar a fermentação e, com isso, produzir melhor tingimento ${ }^{5}$. Por causa dessa prática, os tintureiros, que pertenciam a castas consideradas inferiores na Índia também eram tidos como "impuros".

A estampa chita, embora tenha sido levada ao conhecimento europeu através de Vasco da Gama, por ocasião de sua chegada em Calcutá, em 22 de março de 1498, em que encontrou tecidos de algodão estampados, conforme Fig.1a e 1b, que encantaram toda a sua tripulação, já era conhecida e produzida pelos povos autóctones do continente americano ${ }^{6}$.

A história tradicional conta que Portugal possuía acordos comerciais com a Inglaterra, que lhe fornecia toda a chita de que precisava. E, aí, posso inferir, reside o motivo pelo qual Portugal demorou tanto para começar a produzir chita própria. Registros na história cultural dizem que outra

\footnotetext{
${ }^{4}$ Em Portugal, as estampas de chita, vindas da Índia, seriam conhecidas pelo nome de pintado. Na Holanda, recebe o nome de sits e, na Inglaterra, o tecido estampado de flores é chamado de chintz até hoje.

${ }^{5}$ Essa prática peculiar ainda é utilizada como recurso de tecelagem em regiões rurais de Minas Gerais.

${ }^{6}$ Os conquistadores espanhóis Pizarro e Cortés, menos de um século depois da viagem de Vasco da Gama à Índia em 1498 , encontraram nas Américas do Sul e Central tecidos de algodão, estampados pelos incas e astecas, em tons de vermelho, amarelo, azul, verde e preto. Mas, infelizmente, não se tem informações detalhadas sobre a utilização e confecção da chita pelos mesmos.
} 
Estampa chita: cesura e memória no descontínuo da história dos vencedores

razão para esse atraso é a habitual rejeição lusitana ao trabalho manual. Talvez por causa da influência mulçumana - para eles, a tecelagem era considerada atividade terrível. Tecedor era sinônimo de escravo. Há inclusive ditado popular português, ainda em voga em algumas regiões do interior de Portugal, que afirma: nove décimos de toda estupidez do mundo estava entre os tecelões.

A cesura salvadora, isto é, a interrupção neste episódio da história tradicional, se dá no novo olhar que dirijo aos tecelões, re-significando a sua importância para o crescimento industrial da Europa e comercial entre o Oriente e o Ocidente. A História social da estampa chita conta que nas primeiras fases do processo de industrialização em Portugal, a tecelagem teve importância fundamental. Ela impulsionou a concentração fabril, fazendo com que o setor industrial e o comércio internacional progredissem consideravelmente. A estampa chita passou a ser apreciada e considerada preferência dos consumidores europeus.

Segundo Pedreira (1991, p. 537):

A estampa chita era tecido que podia substituir com vantagens as sedas, tanto em artigos de vestuário como de decoração. A importação de cálicos cresceu consideravelmente e as Companhias das Índias Orientais começaram a organizar feitorias para reunirem esses produtos.

Na cesura ocasionada pela história social da estampa chita, encontro o mesmo tecelão que

Figura 1a - Estampa chita.

Foto produzida pela autora em 06/06/2008.

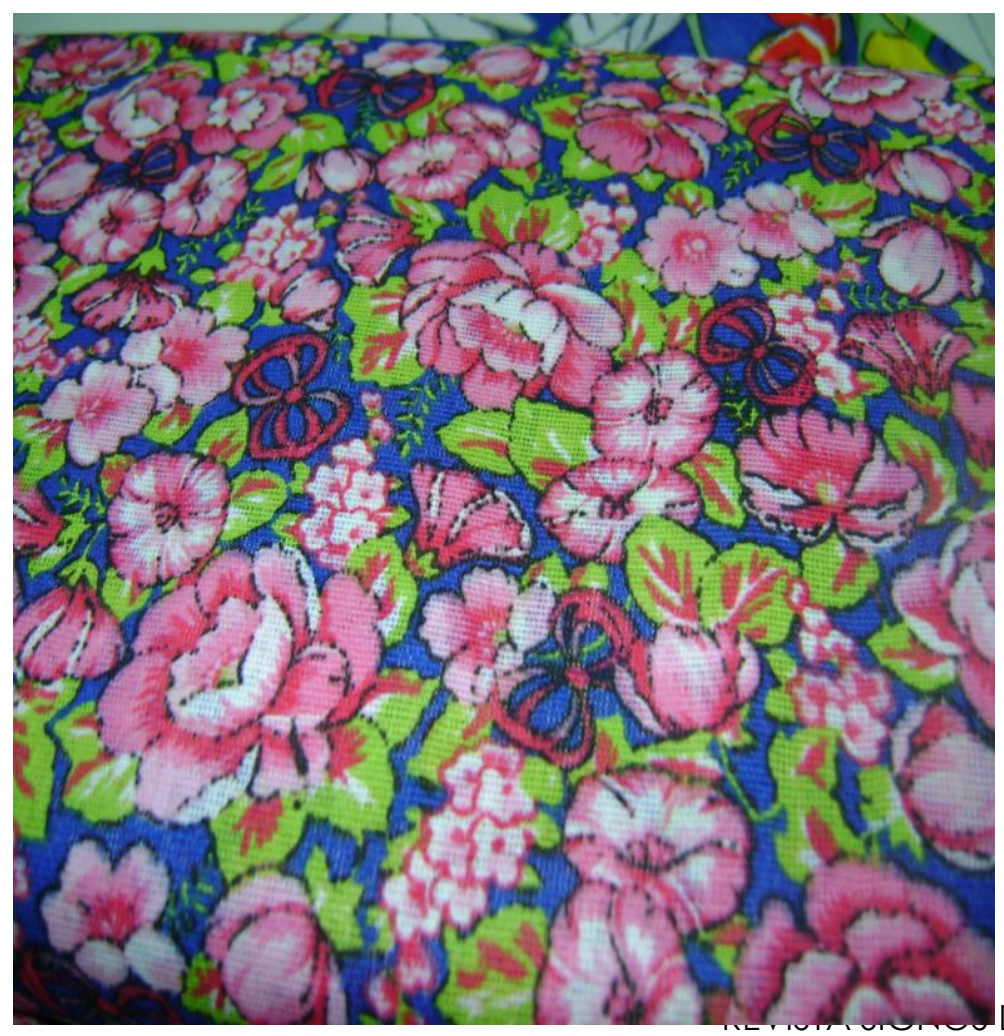
agora não está abaixo de seu produto como afirmou a História dos Vencedores. Ele é importante para o desenvolvimento econômico de Portugal e da Índia. A tecelagem passa a ser fundamental no desenvolvimento industrial europeu, que começa a produzir os estampados principalmente na Inglaterra e a repassá-los para o restante dos países da Europa.

No Oriente, a estampa chita indiana passa ter valor igual ao da seda chinesa. O comércio exterior é impulsionado por esta valorização dos florais da Índia que são vendidos para Portugal e países próximos. Tanto no 
Estampa chita: cesura e memória no descontínuo da história dos vencedores

de Emanuela Francisca Ferreira Silva

Ocidente quanto no Oriente, a estampa chita transforma de maneira significativa o comércio fabril. Ela não possui classe social. É produzida na Europa e na Índia, chegando a substituir a seda no vestuário e na decoração.

Continuando

minha análise, quero fazer considerações acerca de grande artista europeu, que conseguiu retratar através de suas obras a história dos vencidos. Este artista é Johann Moritz

Rugendas, alemão que viajou por todo o Brasil de 1822 a 1825 ,

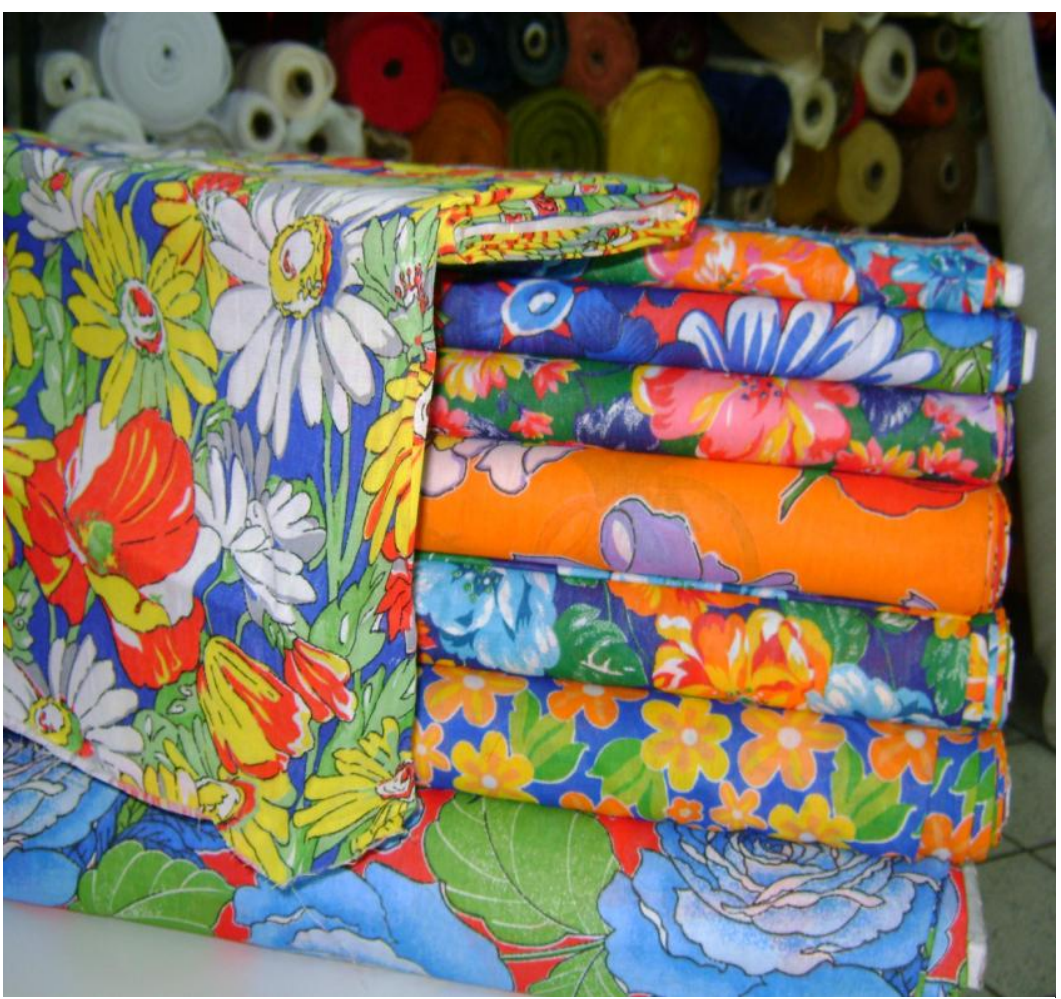

Figura 1b - Variações de estampa chita. Foto produzida pela autora em 06/06/2008. pintando o povo e os costumes brasileiros. Suas obras (ver Fig. 2a e 2b) serão utilizadas nesse trabalho como ilustração, visto que demonstram como a estampa chita está no descontínuo da História dos vencedores.

Observando atentamente as Fig. 2a e 2 b posso perceber como Rugendas retrata a escrava brasileira vestida com saia de chita no século XIX. Ela, a estampa chita, que está vestindo a escrava, é utilizada por Rugendas como traje para os menos abastados. O álbum Viagem Pitoresca através do Brasil (1835), em que aparecem essas imagens, foi extremamente criticado por nele ter sido encontrado mais beleza que verdade.

Segundo Milliet (1998, p.17), “Embora não se possa caracterizar o pensamento de Rugendas pela clareza e elegância, ainda assim suas ideias se revelam menos nebulosas que as de muitos contemporâneos seus". À luz do romantismo, Rugendas pintou e retratou o Brasil do início do século XIX. Mas seu grande diferencial foi retratar os negros, os índios e situações cotidianas do Brasil, com observações que denotam assuntos que só no final do século XX começaram a fazer parte de pesquisas sociológicas e antropológicas.

Ao retratar escravas vestidas com a estampa chita, Rugendas parece ver aquilo que ninguém mais percebe. Eles, os escravos, também podem utilizar as cores e formas desta estampa assim como seus irmãos que se encontram na África. É como se Rugendas estivesse tentando representar 
através da estampa: a força e a alegria que ela evoca no intrínseco, em que todas as classes têm acesso. São apenas suposições, outros trabalhos vindouros poderão ajudar a justificar com mais clareza essas afirmações.

Aparentemente, pela chita que veste as escravas, fica evidente a denotação que acabou reverberando ao longo do tempo de "tecido dos desvalidos", "tecido de qualidade inferior" ou “tecido barato", significados estes, atribuídos à estampa chita, que foram os responsáveis por situála como "popular". Mas, é no olhar de alguns pintores europeus em passagem pelo Brasil, como Nicolas-Antoine Taunay e Jean Baptiste Debret, que reside o contexto histórico que expõe formas diversas de ocupações e atividades realizadas pelos escravos no período colonial cosmopolita. Como já afirmei, é Rugendas quem melhor retrata este contexto. Borba de Morais (1998, p.13) observa que "Debret não tinha o traço tão firme como o de Rugendas". Analisando as obras destes artistas constatei que somente nas obras de Rugendas é possível encontrar a estampa chita pintada nas roupas das brasileiras que foram escravas.

Havia os escravos que trabalhavam no campo, no cultivo da cana e do algodão, por exemplo; os escravos de ofício, especializados nos cuidados da moagem da cana ou nas atividades ligadas à carpintaria, olaria e ferraria; os escravos domésticos, escolhidos entre os que se mostravam mais socializáveis e que eram os responsáveis pelo funcionamento da casa grande; e os escravos de

Figura 2a: quadro do pintor alemão Rugendas - O Brasil de Rugendas, 1980. Négre e Négresse de Bahia, $2^{\mathrm{a}}$ div- $\mathbf{p l . 8}$

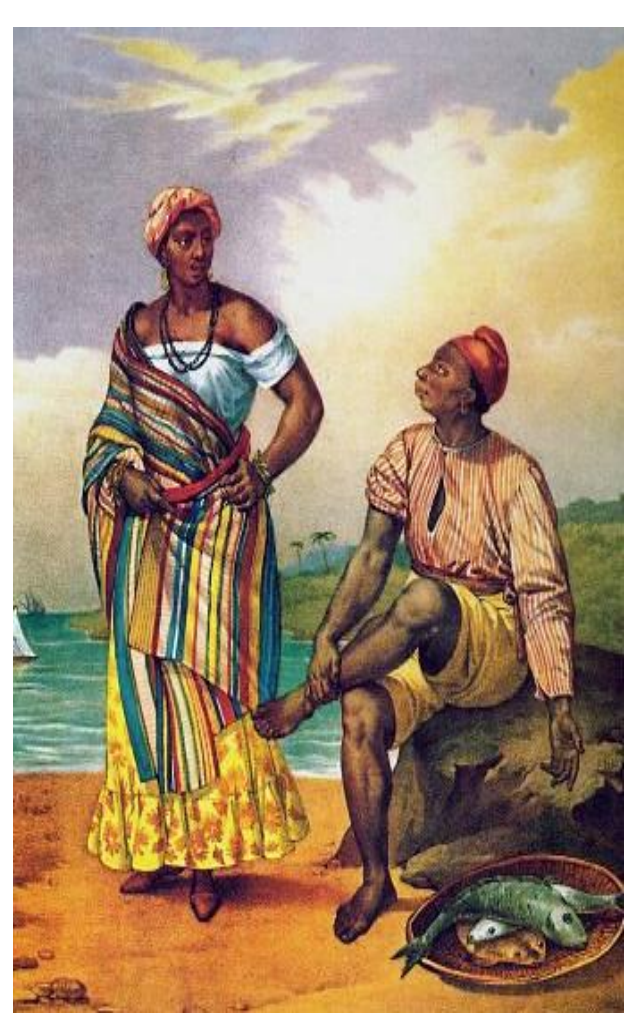

ganho, que desempenhavam tarefas relacionadas à obtenção de renda, dividida com seus senhores e que garantiria a alforria.

Por isso, é leviano demais sustentar a imagem do escravo ligado a afazeres pesados e cruéis, quase que despido totalmente ou apenas coberto por trapos, como algumas iconografias revelam. Sabe-se que os escravos que exerciam algum ofício eram mais valorizados por ocasião da venda. $\mathrm{E}$ que o gosto dos colonos por roupas luxuosas e o ócio a que se dedicavam constituíram aspectos favoráveis ao surgimento de uma mão-de-obra voltada ao "mercado das vaidades".

É nos registros de viajantes estrangeiros ao Brasil, contudo, tendo em vista a escassez de documentos do período, que os homens da Colônia aparecem como poucos laboriosos e, por isso mesmo, com nítida preferência à administração do trabalho dos cativos. Os apontamentos dão 
conta de que as mulheres mais abastadas também pouco se movimentavam. Daí serem citadas como obesas, desleixadas e mal-humoradas, já que ficavam deitadas em suas esteiras, sendo servidas, constantemente e para tudo, pelas escravas. Não é à toa que os hábitos de homens e mulheres da Colônia escandalizaram os europeus que por aqui passaram nos séculos XVII e XVIII, registrando em suas anotações ser o Brasil o "berço da preguiça". E não é por acaso também que as artes da costura e do corte de tecidos acabaram se tornando um dos trabalhos mais importantes dos escravos que se dedicavam a tal ofício, juntamente com o serviço da casa como já me referi anteriormente.

Nas cenas urbanas de Rugendas, os escravos são figuras elegantes, bem trajadas e com retoques de

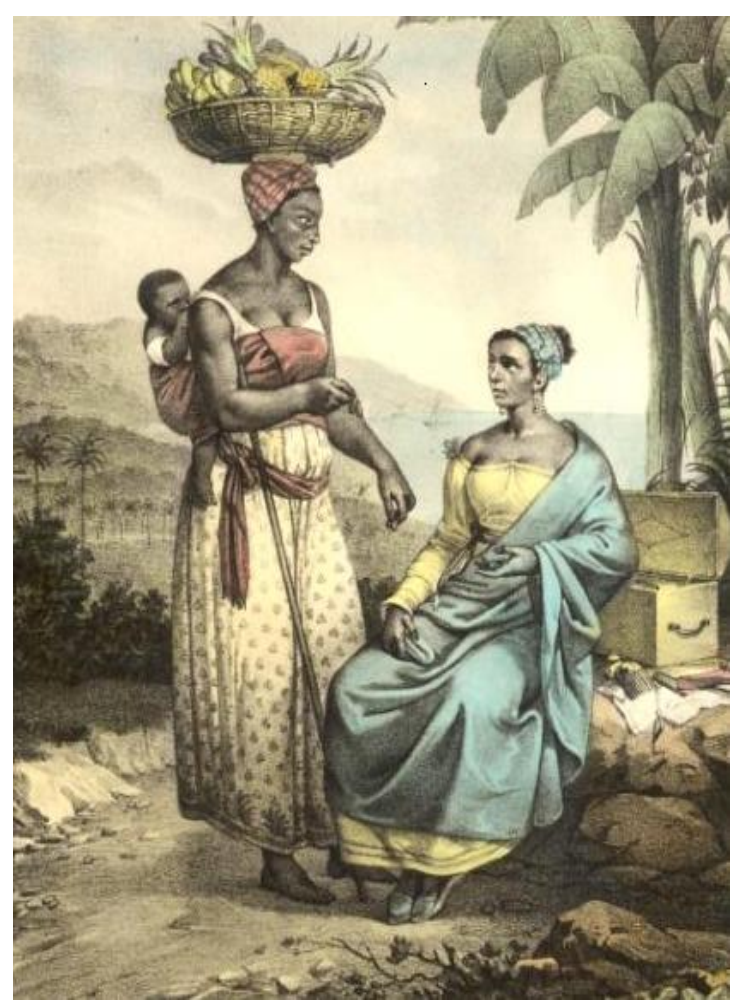

Figura 2b: quadro do pintor alemão Rugendas - O Brasil de Rugendas, 1980. Negrésses de Rio de Janeiro, $2^{\text {a }}$ div. - pl 7 sedução. Percebe-se o apuro no trajar e nos acessórios (colares, turbantes, xales, pulseiras). Há ainda certo ar festivo na escolha das estampas, o que destoa da indumentária dos brancos na visão de Taunay: austera e sem extravagâncias. Exemplo disso são os retratos da família Real. As princesas portuguesas foram registradas com vestidos fechados, golas brancas de renda e poucas jóias. Em alguns momentos, uma moda ultrapassada, bem diferente da corte de Napoleão Bonaparte, também retratada por Taunay. Mas, as pinturas do artista mostram ainda figuras da nobreza no Brasil se divertindo em ambientes bucólicos: mulheres graciosas com seus chapeuzinhos amarrados com fitas no queixo, decotes comportados e mangas fofas em vestidos de tecidos leves. Homens alinhados, em coletes e casacas, com calças justas que valorizavam as meias e os sapatos delicados.

\section{CONSIDERAÇÕES FINAIS}

Neste ponto do trabalho, volto o olhar para a advertência de Benjamin, quando fala que a verdade da narração não deve ser buscada no seu desenrolar, mas precisamente naquilo que lhe escapa, nos seus silêncios. Por isso, prefiro considerar a estampa chita no descontínuo da história tradicional. 
Estampa chita: cesura e memória no descontínuo da história dos vencedores

Através da memória da estampa chita foi possível encontrar outro passado diferente daquele contado nos livros de história tradicional. Os tecelões e os escravos, que são considerados castas inferiores, aparecem no descontínuo como figuras dotadas de identidade e valor próprios. A chita estampa estes dois personagens com características que lhe outorgam mais que um simples lembrar o passado. É a retomada ou o voltar/renovação que quebra a continuidade da cronologia tranquila e imobiliza seu fluxo, instaurando o instante e a instância da salvação.

A tecelagem foi de grande importância para o desenvolvimento econômico europeu e a chita foi o pilar desse crescimento. Estampando os trajes dos brasileiros que foram escravos, Rugendas retrata as diversas funções sociais que o negro tinha no Brasil-colônia. Ele é sensual, elegante e sua vestimenta denota isso. A chita consegue denotar esta outra faceta dos escravos e dos tecelões que não está na linha contínua da história de longa duração.

A ruptura na linguagem é a paragem no contínuo da história dos vencedores. A cesura neste espaço-tempo foi feita pela memória da estampa chita, que consegue, através de seus pequenos rastros nos espaçamentos da história, trazer para o presente novo passado, em que outras verdades podem aparecer fora dos discursos tradicionais, ou seja, naquilo que lhes escapa.

\section{REFERÊNCIAS BIBLIOGRÁFICAS:}

BENJAMIM, W. Magia e técnica, Arte e Política. Ensaios sobre Literatura e história da cultura. São Paulo: Editora Brasiliense, 1987.

COSTA, S; BERMAN, D.; HABIB, R. 150 Anos da Indústria Têxtil Brasileira. Rio de Janeiro: SENAI - CETIQT/Texto e Arte, 2000.

GAGNEBIN, J. Lembrar escrever esquecer. São Paulo: Copyright Editora, 2006.

GAGNEBIN, J. História e Narração em Walter Benjamim.São Paulo: Editora Perspectiva, 2004.

HOBSBAWUM, E. Era dos Extremos - o breve século XX: 1914-1991. São Paulo: Companhia das Letras, 1995.

HOBSBAWN, E. Sobre História. São Paulo: Companhia das Letras, 1998.

LE GOFF, J. A História Nova. São Paulo: Martins Fontes, 2005.

LE GOFF, J. História e Memória. São Paulo: Copyright Editora, 2003.

MELlÃO, R.Que Chita Bacana. São Paulo: Ed. A Casa-Casa Museu do Objeto Brasileira, 2005.

MILLER, S.; BORBA, R.;VILHAÇA, Antônio Carlos. O Brasil de Rugendas. 100 pranchas coloridas. Rio de Janeiro: Editora Itatiaia, 1980. 
Estampa chita: cesura e memória no descontínuo da história dos vencedores

PEDREIRA, José Miguel. Indústria e Negócio: a estamparia na região de Lisboa, 1780-1880. Lisboa, 1991, disponível em www.domíniopublico.com. Acessado em 13/11/2008.

SELIGMANN-SILVA, Márcio. Reflexões sobre a Memória, a História e o esquecimento. São Paulo: Martins Fontes, 1999.

Artigo recebido em 2/6/2009.

Aprovado em 10/9/2009. 